92

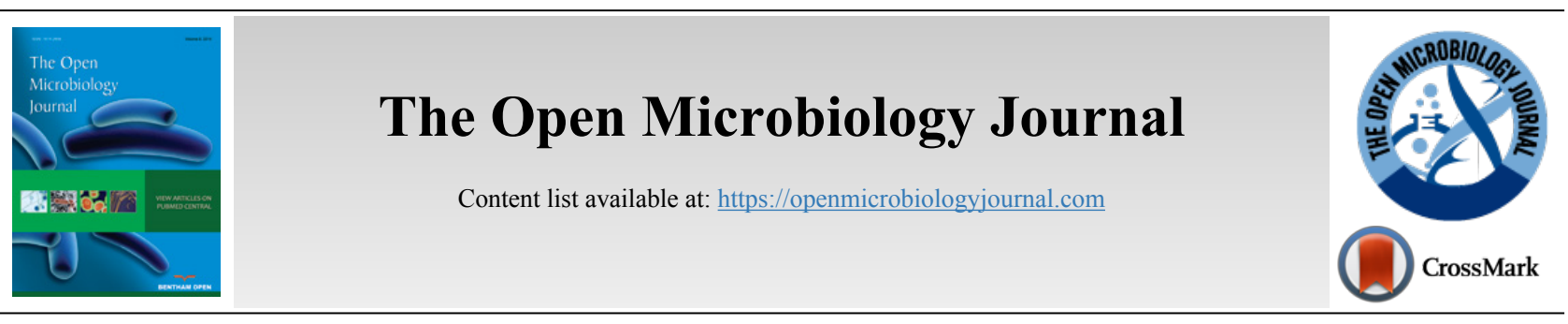

LETTER/\$ 5 7,\&/ (

\title{
Identification of Immunogenic Candidate for New Serological Tests for Brucella melitensis by a Proteomic Approach
}

Valentina Paci ${ }^{1}$, Pierina Visciano ${ }^{2}$, Ivanka Krasteva ${ }^{1}$, Tiziana Di Febo ${ }^{1}$, Fabrizia Perletta ${ }^{1}$, Chiara Di Pancrazio ${ }^{1}$ Federica D’Onofrio ${ }^{2}$, Maria Schirone ${ }^{2, *}$, Manuela Tittarelli ${ }^{1}$ and Mirella Luciani ${ }^{1}$

${ }^{1}$ Istituto Zooprofilattico Sperimentale dell'Abruzzo e del Molise “G. Caporale”, Via Campo Boario, 64100 Teramo, Italy

${ }^{2}$ Faculty of Bioscience and Technology for Food, Agriculture and Environment, University of Teramo, Via R. Balzarini 1, 64100 Teramo, Italy

\begin{abstract}
:
Background:

The diagnosis of brucellosis by serological tests is based on antigen suspensions derived from smooth lipopolysaccharide extracts, which can give false positive results linked to cross-reactivity with other Gram-negative microorganisms, especially Yersinia enterocolitica O:9 and Escherichia coli O157:H7.

Objective:

The objective of the present study was the characterization by proteomic analysis of specific immunogenic proteins not associated with smooth lipopolysaccharide to improve the diagnostic tests used in the ovine brucellosis eradication programs.

Methods:

The serum from a sheep positive to Brucella melitensis was treated to eliminate all antibodies against such lipopolysaccharide and highlight the reaction towards the immunoreactive proteins in Western Blotting.

Results:

The immunoreactive bands were identified by nLC-MS/MS and through bioinformatic tools, it was possible to select 12 potential candidates as protein antigens specific for Brucella melitensis.

Conclusion:

The detection of new antigens not subjected to cross-reactivity with other Gram-negative microorganisms can offer an additional tool for the serological diagnosis of such disease.
\end{abstract}

Keywords: Brucellosis, Cross-reactivity, Western blotting, Mass spectrometry, Bioinformatics, Serological tests.

\begin{tabular}{l|l|l|r} 
Article History & Received: December 29, 2020 & Revised: May 17, 2021 & Accepted: May 25, 2021
\end{tabular}

\section{INTRODUCTION}

The brucellosis can affect humans by the contact with ill animals and their parts, such as carcasses or abortion derivatives, and by consumption of contaminated raw milk and unpasteurized dairy products [1]. It is characterized by an acute febrile status known as undulant fever, chills or shaking rigors, malaise, generalized aches, headache, anorexia, and general weakness [2], and other long term clinical signs such as arthral-

* Address correspondence to this author at the Faculty of Bioscience and Technology for Food, Agriculture and Environment - University of Teramo, Via R. Balzarini 1, 64100 Teramo, Italy; Tel: +390861 266911;

E-mail: mschirone@unite.it gia, myalgia, hepatomegaly or hepatitis, endocarditis, and meningitis [3]. The effectiveness of the control and prevention of brucellosis depends on the timely diagnosis and isolation of infected animals. The serological tests currently in use for its diagnosis are described in the OIE Manual [4] and internationally recognized. Such tests are based on antigen suspensions derived from smooth Brucella or lipopolysaccharide extracts, but they can result in false-positive serological reactions if the animal has developed antibodies against other Gram-negative bacteria, in particular, Yersinia enterocolitica 0:9 and Escherichia coli O157:H7 [5]. The cause of this cross-reactivity is due to the presence of smooth 
lipopolysaccharide (sLPS). It is a dominant component of almost all Gram-negative bacterial outer membranes, generally consisting of a predominantly lipophilic component lipid A, a core oligosaccharide part and O-polysaccharide (OPS) section called $\mathrm{O}$-antigen [6]. The O-antigens are highly immunogenic and conserved among different Gram-negative strains and species, and therefore antibodies developed against sLPS of $E$. coli or Y. enterocolitica can also bind Brucella LPS. Therefore, the analyses of Brucella strains at protein level can serve to identify Brucella specific immunogenic targets, that are required to improve the current serological tests to better support the disease eradication plans.

In the present study, Brucella melitensis (BM) immunogenic proteins were investigated to detect epitopes able to distinguish true BM positive animals from those infected with $Y$. enterocolitica $\mathrm{O}: 9$ and $E$. coli $\mathrm{O} 157: \mathrm{H} 7$, the most important Brucella cross-reactive bacteria. The first step was the localization of proteins to discard the cytosolic ones, because the proteins of the envelope are those that are into contact with the host immune system and stimulate the production of antibodies. Such envelope proteins were studied for their immunogenic potential with the aim to discard the homologue proteins with the major cross-reactive Gramnegative bacteria. Then, a depletion approach was adopted: a BM positive serum was pre-treated with purified sLPS to remove all anti-sLPS antibodies. Western Blotting (WB) analyses were performed to detect specific immunoreactive bands of BM not associated with sLPS. The immunoreactive bands were identified by nLC-ESI-MS/MS and the exposed Bcell epitopes were predicted through bioinformatics tools, as reported by Paci et al. [7]. The bioinformatics pipeline, used to analyze the data obtained by mass spectrometry, was developed to identify potential B-cell target protein candidates for serological diagnosis.

\section{MATERIALS AND METHODS}

The bacterial strains (BM $16 \mathrm{M}$ ), reference antisera and the cultivation of Brucella for proteomic analyses were the same used by Paci et al. [7]. To identify BM immunogenic proteins that are not associated with sLPS, the positive serum for BM was treated for $4 \mathrm{~h}$ at $37{ }^{\circ} \mathrm{C}$, with sLPS antigen produced according to OIE Manual.

BM total proteins $(5 \mu \mathrm{g} /$ well) were separated by SDSPAGE using NuPage ${ }^{\circledR} 4-12 \%$ Bis-Tris pre-cast gels (Life Technologies) at a constant voltage of $200 \mathrm{~V}[7,8]$ and transferred onto a nitrocellulose membrane using the iBlot Dry Blotting system (Life Technologies) [9]. After blocking with $5 \%$ skim milk in PBS $+0.05 \%$ Tween 20 (PBST) for $2 \mathrm{~h}$, the membranes were cut into strips, which were incubated with untreated and sLPS-treated sera diluted 1:100 in PBST $+2.5 \%$ skim milk and then with Protein G-peroxidase conjugate (Sigma) diluted 1:100000 for $1 \mathrm{~h}$, at room temperature.

The antigen-antibody reactions were visualized by adding the AmershamTM ECL Select ${ }^{\mathrm{TM}}$ Western Blotting Detection Reagent (GE Healthcare) and the images were acquired using the ChemiDoc MP (Bio-Rad) and the Image Lab Software, version 4.0 (Bio-Rad).

Mass spectrometry analyses were performed at IFOM (the
FIRC Institute of Molecular Oncology, Milan - Italy) facilities. Two slices of SDS-PAGE gel were excised; then proteins were treated with $10 \mathrm{mM}$ DTT and $55 \mathrm{mM}$ IAA, and they were digested with trypsin. After addiction of $0.1 \%$ formic acid, peptides were concentrated and analyzed by nLC-MS/MS using an UPLC EASY-nLC 1000 connected to a quadrupole Orbitrap QExactive-HF (Thermo Fisher) and with a gradient (from 5 to $100 \% \mathrm{~B}$ ) of $2 \%$ acetonitrile $/ 0.1 \%$ formic acid (eluent A) and $80 \%$ acetonitrile $/ 0.1 \%$ formic acid (eluent B) [10].

Raw data were processed with Proteome Discoverer (version 1.4.1.14, Thermo Scientific) and Mascot (version 2.6.0, Matrix Science), searching against the BM 16M. The obtained data were examined with Scaffold (version 4.8.9, Proteome Software Inc.) and only proteins with greater than $99.0 \%$ probability and containing at least 3 peptides (greater than $95 \%$ probability) were accepted. Therefore, only proteins detected in at least 2 out of 3 biological replicates were included in bioinformatic analysis. The data were examined using the following software: LipoP 1.0 Server [11]; TMHMM Server version $2.0[12,13]$ and SignalP 4.1 Server [14]; PSORTb version 3.0.2 [15] and CELLO version 2.5 [16, 17].

In order to evaluate the protein antigenicity, the noncytosolic proteins were examined using Vaxign tool [18 - 20] and VaxiJen [21]. Such software permitted the prediction of protective antigens, but Vaxign tool integrated open source and internally developed programs and it was specific to vaccine target prediction, while VaxiJen analyzed physicochemical properties of proteins without the need to sequence alignment. The proteins with adhesion scores (obtained by Vaxign tool) higher than 0.5 and between 0.4 and 0.5 were considered antigens with high and intermediate antigenic potential, respectively [22]. The adhesion score measured the probability that the protein is attached to the host cells and it is mediated by adhesins, which are important for bacterial colonization and could be target for vaccine development [23].

Furthermore, high potential antigenic proteins were analyzed by BLASTp to eliminate BM proteins homologous with those of $Y$. enterocolitica 0:9 (taxid:630), E. coli O157:H7 (taxid:562) and proteins similar to those of the Bovidae family (identity greater than $35 \%$ ). MFDP2 version 2.00 Disorder predictor [24] was used to eliminate proteins with disorder more than $25 \%$.

NetSurfP version 1.1 [25] and BepiPred version 1.0 Server [26] were used to predict the protein secondary structure and B-cell linear epitopes, respectively.

\section{RESULTS AND DISCUSSION}

\subsection{Western Blotting}

Untreated sera reacted with proteins with molecular weight ranging between 160 and $15 \mathrm{kDa}$, while sLPS treated sera reacted with 2 areas at $160-55 \mathrm{kDa}$ (BM1) and 18-30 kDa (BM2). Areas with MW at 80-55 kDa (BM1), and 30-18 kDa (BM2) were examined by nLC-ESI-MS/MS. Protein bands with MW ranging from 55 and $30 \mathrm{kDa}$ were recognized by antibodies vs SLPS.

The negative serum samples did not show a reaction with the BM protein extracts (Fig. 1). 


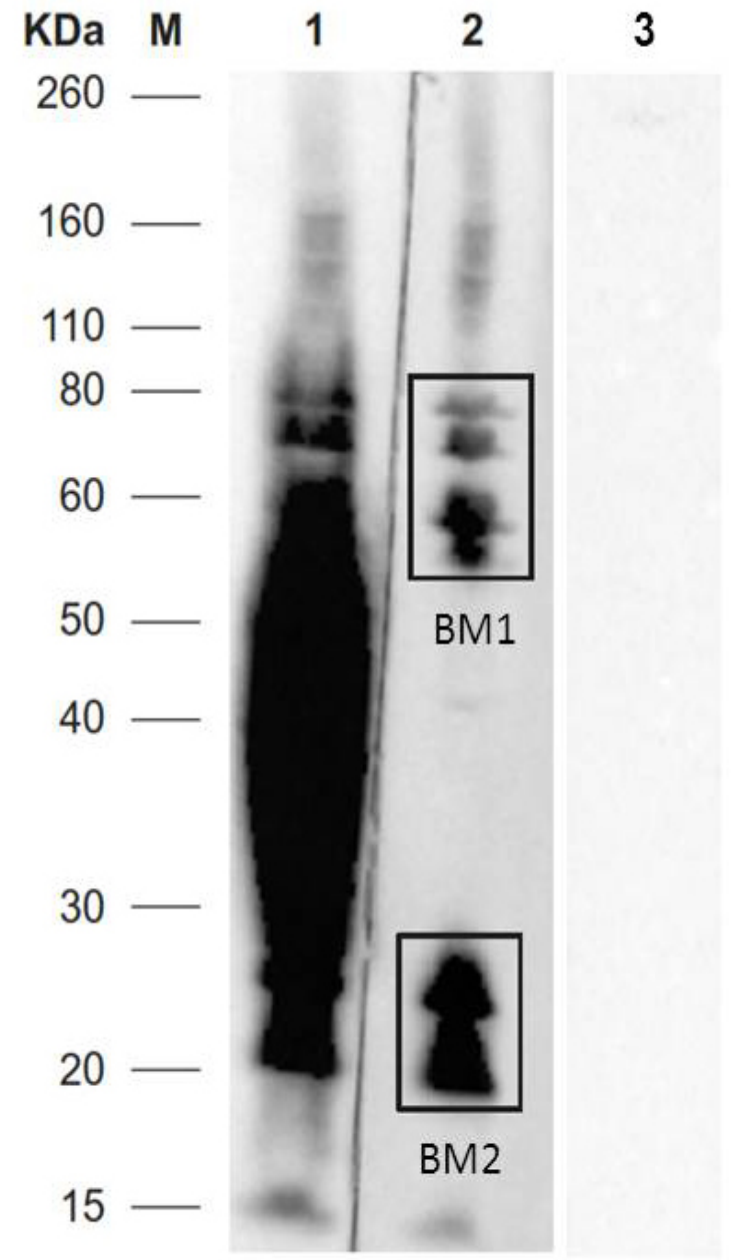

Fig. (1). Western blot of Brucella melitensis antigens against a serum from a $B$. melitensis infected sheep untreated (lane 1), pre-treated to remove anti-sLPS antibodies (lane 2) and a serum from a Brucella spp. negative sheep (lane 3 ). The proteins were separated on a $4-12 \%$ polyacrylamide gel. The gel was electroblotted onto nitrocellulose membrane (20 V, $1 \mathrm{~min} ; 23 \mathrm{~V}, 4 \mathrm{~min} ; 25 \mathrm{~V}, 2 \mathrm{~min})$ and $\mathrm{WB}$ analysis was performed with antisera from $B$. melitensis infected sheep untreated and pre-treated. The two gel slices analyzed by nLC-ESIMS/MS are indicated as follows: BM1 and BM2.

\subsection{Mass Spectrometry Analysis (nLC-ESI-MS/MS)}

The number of proteins identified by mass spectrometry in BM1 and BM2 SDS-PAGE gel area was 526 and 432, respectively. Some proteins were present in both bands and the repeated ones were eliminated. According to the validation criteria, 737 proteins were identified. Further details on the identified proteins were provided as Supplementary material.

\subsection{Prediction of Brucella melitensis Immunogenic Proteins}

In order to identify $\mathrm{BM}$ immunogenic proteins for the improvement of the current serological tests, immunoreactive bands not associated with sLPS were identified by WB and subsequently analyzed by nLC-ESI-MS/MS.

In Fig. (2), the workflow for the prediction of protein candidates was presented. A total of 737 proteins were identified in BM1 and BM2 gel slices (Fig. 1), of which 270 (36.6\% of total proteins) were envelope proteins. Then, 69 with "high potential of antigenicity" were identified using the Vaxign tool (adhesion probability greater than 0.5). Among these, 12 proteins were discarded because they showed similarities with other proteins present in humans, pigs, and mice.

Furthermore, 34 proteins showing similarity (identity greater than $35 \%$ by BLASTp) with $Y$. enterocolitica and/or $E$. coli and with proteins belonging to the family Bovidae (2) were discarded. It is reported that $Y$. enterocolitica O:9 and E. coli O157:H7 are the most important cross-reactive bacteria with Brucella.

Additional proteins were discarded as previously investigated and resulting cross-reactive (2 proteins: Q8YE89, Q8YHH8 reported by Liang et al. [27]) or showing an unacceptable degree of disorder (7 proteins had a degree of disorder more than 25\%, by MFDp2). Disorder proteins lack fixed three-dimensional structures, which is required for the correct and unique function of a protein. These proteins need special tools to be analyzed, although they are functionally important proteins and complement the function of ordered proteins [28]. Table 1 showed the 12 candidate proteins identified and ordered according to their predicted immunogenicity. BepiPred predicted 191 epitopes of BM, NetSurfP and THMM 125 exposed epitopes.

Table 1. Brucella melitensis predicted immunogenic proteins.

\begin{tabular}{|c|c|c|c|c|c|c|}
\hline $\begin{array}{c}\text { UniProt } \\
\text { Accession } \\
\text { Number }\end{array}$ & Protein Name & $\begin{array}{c}\text { Adhesion } \\
\text { Probability }^{\text {a }}\end{array}$ & $\begin{array}{l}\text { Protective } \\
\text { Antigen }^{\mathrm{b}}\end{array}$ & $\begin{array}{c}N^{\circ} \text { solvent } \\
\text { exposed } \\
\text { epitope }\end{array}$ & $\begin{array}{c}\begin{array}{c}\text { Y. enterocolitica } \\
\text { proteins } \\
\text { Cover-identity \% }\end{array} \\
\text {. }\end{array}$ & $\begin{array}{l}\text { E. coli proteins } \\
\text { Cover-identity \% }\end{array}$ \\
\hline Q8YDS0 & Heme transporter BhuA & 0.713 & 0.602 & 19 & $42-26.6$ & $38-30.2$ \\
\hline Q8YHY8 & Metal chelate outer membrane receptor & 0.650 & 0.631 & 17 & $97-25.7$ & $95-29.8$ \\
\hline Q8YGF8 & Hypothetical protein & 0.619 & 0.696 & 13 & $\mathrm{NSS}^{\mathrm{c}}$ & $\mathrm{NSS}^{\mathrm{c}}$ \\
\hline Q8YDZ8 & Uncharacterized protein & 0.517 & 0.729 & 7 & NSS & NSS \\
\hline COREV2 & Porin opacity type & 0.743 & 0.629 & 7 & NSS & $93-30.3$ \\
\hline Q8YF11 & Trehalose/maltose binding protein & 0.702 & 0.497 & 13 & $11-25.0$ & $77-24.8$ \\
\hline Q8YG56 & Porin Omp2b & 0.602 & 0.666 & 7 & NSS & NSS \\
\hline Q8YH42 & $\begin{array}{c}\text { Membrane lipoprotein lipid attachment site } \\
\text { containing protein }\end{array}$ & 0.736 & 0.510 & 8 & $96-24.2$ & $95-23.3$ \\
\hline Q8YID7 & Uncharacterized protein & 0.682 & 0.541 & 7 & NSS & $93-26.0$ \\
\hline
\end{tabular}




\begin{tabular}{|c|c|c|c|c|c|c|}
\hline $\begin{array}{c}\text { UniProt } \\
\text { Accession } \\
\text { Number }\end{array}$ & Protein Name & $\begin{array}{l}\text { Adhesion } \\
\text { Probability }^{\text {a }}\end{array}$ & $\begin{array}{l}\text { Protective } \\
\text { Antigen }^{\mathrm{b}}\end{array}$ & $\begin{array}{c}N^{\circ} \text { solvent } \\
\text { exposed } \\
\text { epitope }\end{array}$ & $\begin{array}{c}\text { Y. enterocolitica } \\
\text { proteins } \\
\text { Cover-identity \% }\end{array}$ & $\begin{array}{l}\text { E. coli proteins } \\
\text { Cover-identity \% }\end{array}$ \\
\hline CORMW9 & Extracellular ligand-binding receptor & 0.609 & 0.588 & 5 & $89-22.9$ & $91-24.5$ \\
\hline Q8YBP0 & $\begin{array}{l}\text { Putative ABC transporter peptide-binding } \\
\text { protein }\end{array}$ & 0.509 & 0.491 & 9 & $57-29.5$ & $85-32.4$ \\
\hline Q8YIM8 & Uncharacterized protein & 0.504 & 0.496 & 13 & NSS & NSS \\
\hline
\end{tabular}

Legend: ${ }^{\mathrm{a}}=$ Vaxign threshold: $0.5 ;^{\mathrm{b}}=$ VaxiJen threshold: $0.4 ;^{\mathrm{c}}=$ No significant similarity found.

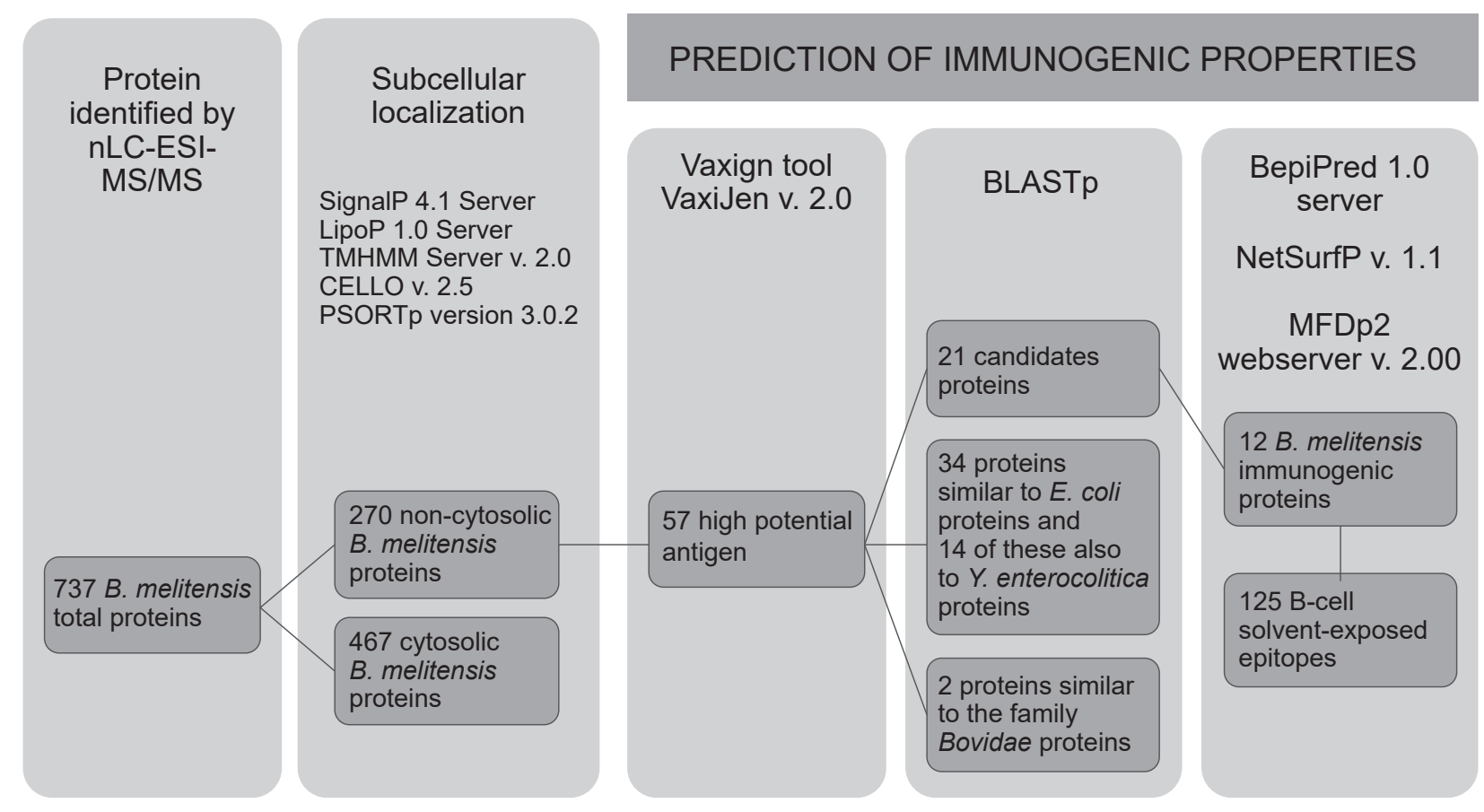

Fig. (2). Overview of bioinformatics tools for prediction of Brucella melitensis immunogenic proteins.

The control of brucellosis is primarily based on its rapid and precise diagnosis, but the conventional methods require a long time of analysis and biosafety level 3 laboratories. For this reason, the serological tests are usually preferred, even if they have a low specificity due to cross-reactivity with other Gramnegative bacteria resulting in false positive reactions [29]. More recently, immunoproteomic methods able to identify new antigens of interest for serodiagnosis have been implemented, not only for Brucella abortus, but also BM and Brucella suis [30]. In the present study, proteomics and bioinformatics analyses focusing on $\mathrm{BM}$ envelope proteins were combined to identify BM specific immunogenic targets and improve sensitivity and specificity of the current serological tests. Then, $12 \mathrm{BM}$ immunogenic proteins potentially able to discriminate BM infected animals from those infected by $Y$. enterocolitica and $E$. coli were identified. Seven of these were predicted as outer membrane proteins (OMPs); the remaining 5 were predicted as periplasmic. Four out of 12 immunogenic proteins are involved in the transport of substances; the best known is Porin OMP2b (Q8YG56) that allows the small hydrophilic materials to across the outer membrane through the formed diffusion pores [31]. For the other proteins, there are no data available in the literature on their immunogenicity.
This study demonstrated that bioinformatic analysis is a faster and cheaper approach to identify potential targets than traditional laboratory identification techniques also for microorganisms belonging to risk group 3, such as BM. However, the bioinformatic software remains only a predictive tool and the obtained results should be confirmed by the conventional methods.

\section{CONCLUSION}

The improvement of serological tests for brucellosis persists as an urgent need for a better diagnosis and control of the disease. The combination of immunoproteomic approach and subsequent in silico analyses to screen B-cell epitopes identified 12 potential candidates as protein antigens specific for BM. The development of diagnostic tests based on new serological antigens not subjected to cross-reactivity with other Gram-negative bacteria can offer an additional tool for the eradication of ovine brucellosis.

\section{AUTHORS' CONTRIBUTIONS}

VP and ML designed the study. VP, IK and FDO performed the experiments. VP, PV, IK, TDF, FP, CDP, FDO, MS, MT and ML performed the data analysis. VP, PV, IK, MS 
and ML drafted the manuscript. All authors contributed to the interpretation of the results, provided critical feedback, contributed to the writing of the manuscript and have approved the final version.

\section{ETHICS APPROVAL AND CONSENT TO PARTI- CIPATE}

Not applicable.

\section{HUMAN AND ANIMAL RIGHTS}

No animals/humans were used for studies that are the basis of this research.

\section{CONSENT FOR PUBLICATION}

Not applicable.

\section{AVAILABILITY OF DATA AND MATERIALS}

The authors confirm that the data supporting the findings of this research are available within the article.

\section{FUNDING}

This research was funded by the University of Teramo "PROGETTO FARDIB 2019".

\section{CONFLICT OF INTEREST}

The authors declare no conflict of interest, financial or otherwise

\section{ACKNOWLEDGEMENTS}

Declared none.

\section{REFERENCES}

[1] Uzunović S, Skomorac M, Bašić F, Kamberović F, Ibrahimagić A, Dizdarević J. Human brucellosis as an epidemic zoonosis in ZenicaDoboji Canton (Bosnia and Herzegovina) during 2008-2018. Open Infect Dis J 2020; 12: 1-6. [http://dx.doi.org/10.2174/1874279302012010001]

[2] Masjedian Jezi F, Razavi S, Mirnejad R, Zamani K. Immunogenic and protective antigens of Brucella as vaccine candidates. Comp Immunol Microbiol Infect Dis 2019; 65: 29-36. [http://dx.doi.org/10.1016/j.cimid.2019.03.015] [PMID: 31300122]

[3] Dadar M, Shahali Y, Whatmore AM. Human brucellosis caused by raw dairy products: A review on the occurrence, major risk factors and prevention. Int J Food Microbiol 2019; 292: 39-47. [http://dx.doi.org/10.1016/j.ijfoodmicro.2018.12.009] [PMID: 30572264]

[4] World organization for animal health (office international des épizooties: OIE). brucellosis (Brucella abortus, B. melitensis and B. suis) (Infection with B. abortus, B. melitensis and B. suis). In: Manual of diagnostic tests and vaccines for terrestrial animals (Chapter 3.1.4), Paris: OIE 2018; 355-98. Available from: https://www.oie.int/fileadmin/Home/eng/Health_standards/tahm/3.01. 04_BRUCELLOSIS.pdf

[5] Bonfini B, Chiarenza G, Paci V, et al. Cross-reactivity in serological tests for brucellosis: A comparison of immune response of Escherichia coli $\mathrm{O} 157: \mathrm{H} 7$ and Yersinia enterocolitica O:9 vs Brucella spp. Vet Ital 2018; 54(2): 107-14. [PMID: 30019327]

[6] Reyes AWB, Simborio HLT, Hop HT, et al. The two highly immunogenic antigens of Brucella: lipopolysaccharide (LPS) and outer membrane proteins (OMPs). J Prev Vet Med 2015; 39(4): 198-206.

[http://dx.doi.org/10.13041/jpvm.2015.39.4.198]

[7] Paci V, Krasteva I, Orsini M, et al. Proteomic analysis of Brucella melitensis and Brucella ovis for identification of virulence factor using bioinformatics approachs. Mol Cell Probes 2020; 53: 101581. [http://dx.doi.org/10.1016/j.mcp.2020.101581] [PMID: 32428653]

[8] Wareth G, Melzer F, Weise C, Neubauer H, Roesler U, Murugaiyan J. Proteomics-based identification of immunodominant proteins of Brucellae using sera from infected hosts points towards enhanced pathogen survival during the infection. Biochem Biophys Res Commun 2015; 456(1): 202-6.

[http://dx.doi.org/10.1016/j.bbrc.2014.11.059] [PMID: 25446124]

[9] Luciani M, Di Pancrazio C, Di Febo T, et al. IgG antibodies from dourine infected horses identify a distinctive Trypanosomo equiperdum antigenic pattern of low molecular weight molecules. Vet Immunol Immunopathol 2013; 151(1-2): 140-6.

[http://dx.doi.org/10.1016/j.vetimm.2012.11.004] [PMID: 23218944]

[10] Luciani M, Di Febo T, Orsini M, et al. Trypanosoma equiperdum low molecular weight proteins as candidates for specific serological diagnosis of dourine. Front Vet Sci 2018; 5(40): 1-6.

[http://dx.doi.org/10.3389/fvets.2018.00040] [PMID: 29556505]

[11] Juncker AS, Willenbrock H, Von Heijne G, Brunak S, Nielsen H, Krogh A. Prediction of lipoprotein signal peptides in Gram-negative bacteria. Protein Sci 2003; 12(8): 1652-62.

[http://dx.doi.org/10.1110/ps.0303703] [PMID: 12876315]

[12] Sonnhammer ELL, von Heijne G, Krogh A. A hidden Markov model for predicting transmembrane helices in protein sequences. Proc Int Conf Intell Syst Mol Biol 1998; 6: 175-82. [PMID: 9783223]

[13] Krogh A, Larsson B, von Heijne G, Sonnhammer EL. Predicting transmembrane protein topology with a hidden Markov model application to complete genomes. J Mol Biol 2001; 305(3): 567-80. [http://dx.doi.org/10.1006/jmbi.2000.4315] [PMID: 11152613]

[14] Petersen TN, Brunak S, von Heijne G, Nielsen H. SignalP 4.0: discriminating signal peptides from transmembrane regions. Nat Methods 2011; 8(10): 785-6.

[http://dx.doi.org/10.1038/nmeth.1701] [PMID: 21959131]

[15] Yu NY, Wagner JR, Laird MR, et al. PSORTb 3.0: Improved protein subcellular localization prediction with refined localization subcategories and predictive capabilities for all prokaryotes. Bioinformatics 2010; 26(13): 1608-15.

[http://dx.doi.org/10.1093/bioinformatics/btq249] [PMID: 20472543]

[16] Yu CS, Lin CJ, Hwang JK. Predicting subcellular localization of proteins for Gram-negative bacteria by support vector machines based on n-peptide compositions. Protein Sci 2004; 13(5): 1402-6. [http://dx.doi.org/10.1110/ps.03479604] [PMID: 15096640]

[17] Yu CS, Chen YC, Lu CH, Hwang JK. Prediction of protein subcellular localization. Proteins 2006; 64(3): 643-51.

[http://dx.doi.org/10.1002/prot.21018] [PMID: 16752418]

[18] Xiang Z, He Y. Vaxign: A web-based vaccine target design program for reverse vaccinology. Procedia Vaccinol 2009; 1(1): 23-9. [http://dx.doi.org/10.1016/j.provac.2009.07.005]

[19] He Y, Xiang Z, Mobley HLT. Vaxign: the first web-based vaccine design program for reverse vaccinology and applications for vaccine development. J Biomed Biotechnol 2010; 297505: 1-15.

[http://dx.doi.org/10.1155/2010/297505] [PMID: 20671958]

[20] Xiang Z, He Y. Genome-wide prediction of vaccine targets for human herpes simplex viruses using Vaxign reverse vaccinology. BMC Bioinformatics 2013; 14(4): 1-10.

[http://dx.doi.org/10.1186/1471-2105-14-S4-S2]

[21] Doytchinova IA, Flower DR. VaxiJen: A server for prediction of protective antigens, tumour antigens and subunit vaccines. BMC Bioinformatics 2007; 8(4): 1-7.

[http://dx.doi.org/10.1186/1471-2105-8-4] [PMID: 17207271]

[22] Hisham Y, Ashhab Y. Identification of cross-protective potential antigens against pathogenic Brucella spp. through combining pangenome analysis with reverse vaccinology. J Immunol Res 2018; 1474517: 1-15.

[http://dx.doi.org/10.1155/2018/1474517] [PMID: 30622973]

[23] Xiang Z, He Y. Vaxign: A web-based vaccine target design program for reverse vaccinology. Procedia Vaccinol 2009; 1(1): 23-9. [http://dx.doi.org/10.1016/j.provac.2009.07.005]

[24] Mizianty MJ, Peng Z, Kurgan L. MFDp2: Accurate predictor of disorder in proteins by fusion of disorder probabilities, content and profiles. Intrinsically Disord Proteins 2013; 1(1): e24428. [http://dx.doi.org/10.4161/idp.24428] [PMID: 28516009]

[25] Petersen B, Petersen TN, Andersen P, Nielsen M, Lundegaard C. A generic method for assignment of reliability scores applied to solvent accessibility predictions. BMC Struct Biol 2009; 9(51): 1-10. [http://dx.doi.org/10.1186/1472-6807-9-51] [PMID: 19646261] 
[26] Larsen JE, Lund O, Nielsen M. Improved method for predicting linear B-cell epitopes. Immunome Res 2006; 2(2): 1-7.

[http://dx.doi.org/10.1186/1745-7580-2-2] [PMID: 16635264]

[27] Liang L, Leng D, Burk C, et al. Large scale immune profiling of infected humans and goats reveals differential recognition of Brucella melitensis antigens. PLoS Negl Trop Dis 2010; 4(5): e673.

[http://dx.doi.org/10.1371/journal.pntd.0000673] [PMID: 20454614]

[28] Uversky VN. Intrinsically disordered proteins. Brenner's Encyclopedia of Genetics. ${ }^{\text {nd }}$ ed. Academic Press 2013; Vol. 4: pp. 124-6. [http://dx.doi.org/10.1016/B978-0-12-374984-0.01698-3]

[29] Pathak P, Kumar A, Sarangi PP, Bhagyawant S, Thavaselvam D. Cloning, expression and purification of virB10 protein of Brucella melitensis and evaluation of its role as a serological marker for Brucella infection in experimental and natural host. Protein Expr Purif 2018; 145: 53-8.

[http://dx.doi.org/10.1016/j.pep.2017.12.014] [PMID: 29305897]

[30] Poetsch A, Marchesini MI. Proteomics of Brucella. Proteomes 2020; 8(2): 1-17.

[http://dx.doi.org/10.3390/proteomes8020008] [PMID: 32331335]

[31] Paquet JY, Diaz MA, Genevrois S, et al. Molecular, antigenic, and functional analyses of Omp2b porin size variants of Brucella spp. J Bacteriol 2001; 183(16): 4839-47.

[http://dx.doi.org/10.1128/JB.183.16.4839-4847.2001]

[PMID:

\section{(C) 2021 Paci et al.}

This is an open access article distributed under the terms of the Creative Commons Attribution 4.0 International Public License (CC-BY 4.0), a copy of which is available at: https://creativecommons.org/licenses/by/4.0/legalcode. This license permits unrestricted use, distribution, and reproduction in any medium, provided the original author and source are credited. 